\title{
Saccade deficits after a unilateral lesion affecting the superior colliculus
}

\author{
C Pierrot-Deseilligny, A Rosa, K Masmoudi, S Rivaud, B Gaymard
}

\begin{abstract}
A 70 year old patient with a small haematoma largely restricted to the area of the right superior and inferior colliculi is reported. Eye movements were electro-oculographically recorded 17 and 80 days after the onset of the haematoma. At the first examination, latency of lateral reflexive visuallyguided saccades was asymmetrical, both in the gap task (central fixation point switched off $200 \mathrm{~ms}$ before the onset of the lateral target) and in the overlap task (central fixation point remaining switched on). Furthermore, latency of leftward saccades in the overlap task was increased, and accuracy of these saccades was impaired, at both examinations. In the immobility task (fixation straight ahead while lateral targets suddenly occurred) and in the antisaccade task (saccade made away from the lateral target), the percentages of errors (saccades made to the target) were high at the first examination, and noticeably lower at the second. These results suggest that the superior colliculus plays an important role both in the triggering and inhibition of reflexive visually-guided saccades.
\end{abstract}

The triggering of all types of saccades appears to be performed by two suprareticular structures, the superior colliculus (SC) and the frontal eye field (FEF), which both project directly on to the brainstem premotor reticular formations. ${ }^{12}$ In the normal state, however, the degree of involvement of each of these two parallel pathways is different depending upon the types of saccade to be performed. Lesion studies in the monkey suggest that the SC plays an important role in the control of reflexive visually-guided saccades. ${ }^{3-5}$ To date, only one patient with an isolated SC lesion has been studied with saccade recordings: ${ }^{6}$ spontaneous saccades and reflexive visually-guided saccades were impaired. There was also a limited lesion affecting the SC in our patient. Eye movements were electrooculographically recorded using four different paradigms, which tested both the excitatory and inhibitory mechanisms involved during the initiation of reflexive visually-guided saccades. The results lead to a better understanding of the role of the SC in the initiation of these saccades.

\section{Case report}

A 70 year old diabetic man, treated with oral medicines for 10 years, was admitted to hospital for headache and a slight left hemiparesis, which began the day before. He also complained of intermittent slight vertical diplopia, occurring in downward gaze. Neurological examination on admission showed only a cerebellar syndrome in his right arm. There was no obvious ocular motor paresis, and convergence and pupillary reactions were normal. His blood pressure was $220 / 100 \mathrm{~mm} \mathrm{Hg}$. A CT performed on the day of admission, and an MRI performed 17 days later, showed a lesion affecting the right superior and inferior colliculi and possibly the right brachium conjunctivum suggestive of a small haematoma (fig $A, B, C$ ). The headache lasted three days. Eye movements were recorded twice, 17 days and 80 days after the onset. During these two recording sessions the patient was alert and cooperative. His vertical diplopia still occurred occasionally in downward gaze, being due to a slight paresis of the left superior oblique muscle (Lancaster test). There was no diplopia when the eyes moved horizontally in the different saccade paradigms. Visual attention was tested in the first recording session, according to a procedure previously described $;{ }^{7}$ there was no visual neglect. A second MRI was performed the day before the second recording session, showing a small cicatricial lesion affecting the right superior and inferior colliculi (fig D).

\section{Eye movement recordings}

Eye movements were recorded by directcurrent electro-oculography (EOG) in complete darkness with four electrodes (two horizontal temporal, and two vertical on one eye). The head was immobilised by a headrest with a restraining mechanism at the temples. Four saccade paradigms were studied.

The overlap task tested the triggering of reflexive visually-guided saccades. A central fixation point was switched on throughout the task. The subject was instructed to fix this point, and to look as quickly as possible at a lateral target, suddenly occurring $25^{\circ}$ away from the central point, either right or left, 

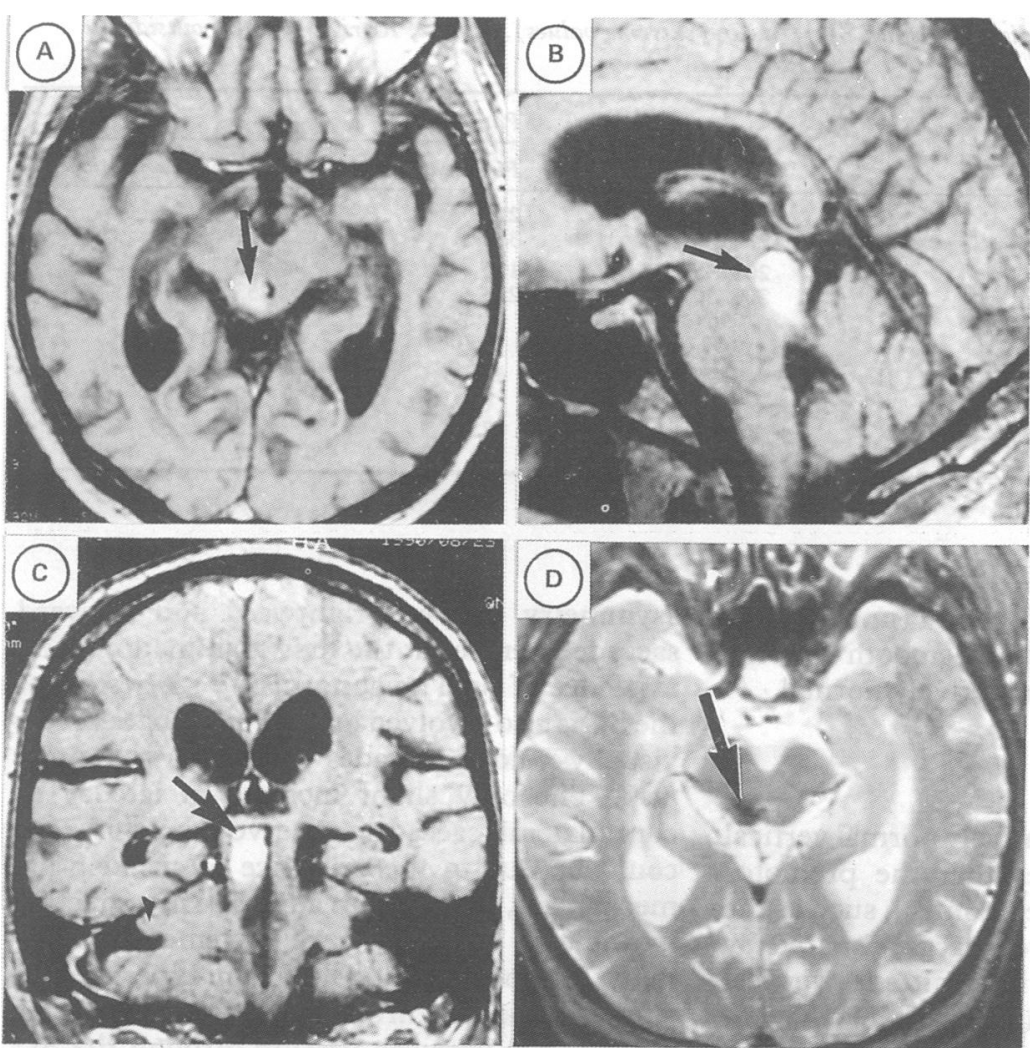

Figure MRI. A, B and C: horizontal, sagittal and coronal sections (T1), respectively, passing through the right superior colliculus, 18 days after the onset. $D$ : horizontal section (T2) passing through the right superior colliculus, 79 days after the onset. The arrows show the lesion.

with unpredictable timing and direction. Latency was the time between the onset of the lateral target and the start of the saccade. Right and left saccade latencies were calculated by averaging 30 measurements in each direction.

The gap task also tested the triggering of reflexive visually-guided saccades. The central fixation point, however, was switched off 200 ms (gap) before the appearance of the lateral target. Apart from switching off the central fixation point, the procedure was the same as for the overlap task. Right and left saccade latencies were calculated by averaging 30 measurements in each direction. To study the accuracy of reflexive visually-guided saccades, the same procedure was repeated, but with the addition of unpredictable amplitude $(10,15$, 20,25 or $30^{\circ}$ ). Right and left saccade gains (amplitude of reflexive visually-guided saccade over amplitude of the target) were calculated by averaging 30 measurements in each direction.

The immobility task tested the inhibition of reflexive visually-guided saccades. The procedure was the same as in the gap task, but the subject was instructed to keep his eyes immobile when the lateral target occurred. If a saccade was made towards the target, this was considered an error. The percentage of errors was determined for each lateral direction (30 stimulations in each case).

The antisaccade task also tested the inhibition of reflexive visually-guided saccades. The procedure was the same as for the gap task and the immobility task, but the subject was instructed to look in the opposite direction to the target, without first looking at it. If the subject looked first at the target, or in the direction of the target, this constituted an error. The percentage of errors was determined for each lateral direction (30 stimulations in each case).

Lateral foveal smooth pursuit and optokinetic nystagmus (OKN) were tested according to a procedure previously described. ${ }^{8}$ Vertical saccades and smooth pursuit were also recorded, but only qualitatively analysed, since EOG is not reliable in the vertical plane.

A control group of 20 age-matched normal subjects (mean age $=70$ years, $\mathrm{SD}=9$ ) was studied using the same saccade paradigms.

\section{Results}

The main results are given in the table. At the first examination, rightward saccade latency in the overlap task was very near the mean saccade latency of controls, but leftward saccade latency was clearly increased, outside the normal range [defined as the mean latency of controls $\pm \mathrm{SD}$ ]. The asymmetry between right and left latencies was significant (Student's $t$ test, $\mathrm{p}<0.01$ ). In the gap task, leftward saccade latency was longer than rightward saccade latency, with significant asymmetry (Student $t$ test, $\mathrm{p}<0.01$ ), but these two latencies were within the normal range. The difference between latency in the overlap task and latency in the gap task was within the normal range, for both rightward saccades [mean (SD) value of control subjects $=18(36)$ $\mathrm{ms}$ ] and leftward saccades [mean (SD) value of control subjects $=16(34) \mathrm{ms}$. Accuracy of rightward saccades in the gap task was normal, but accuracy of leftward saccades was impaired, the gain being outside the normal range. At the second examination, there was an improvement in results in the overlap task and the gap task. Asymmetry between right and left latencies was no longer significant in either task. Latency of leftward saccades in the overlap task had slightly decreased, and the saccade gain in the gap task had increased, though both values remained outside the normal range.

In the immobility task and in the antisaccade task, standard deviations could not be calculated in controls because the distribution of values was not normal. However, at the first examination, most of the patients' results appeared to differ sufficiently from those of controls to be considered abnormal. In the immobility task, the patient made $45 \%$ errors for rightward stimulations and 5\% errors for leftward stimulations. The former percentage was considerably increased compared with controls, who made only very rare errors in such a task (table). In the antisaccade task, percentages of errors were also increased for both sides of stimulation. There was a clear improvement in percentages of errors at the second examination, in both the immobility task and the antisaccade task.

Horizontal foveal smooth pursuit gain and horizontal OKN gain were normal, that is, 
Table Results of saccade paradigms: ${ }^{a}$ mean (SD); ${ }^{b}$ mean (extreme values); $L:$ left; $R$ : right; ${ }^{\star}$ value outside the normal range.

\begin{tabular}{|c|c|c|c|c|c|}
\hline & & & \multirow{2}{*}{$\begin{array}{l}\text { Controls } \\
(n=20)\end{array}$} & \multicolumn{2}{|l|}{ Patient } \\
\hline & & & & First examination & Second examination \\
\hline $\begin{array}{l}\text { Overlap } \\
\text { task }\end{array}$ & $\begin{array}{l}\text { Latency } \\
\text { (ms) }\end{array}$ & $\begin{array}{l}\mathbf{R} \\
\mathbf{L}\end{array}$ & $\begin{array}{l}226(43)^{n} \\
222 .(37)\end{array}$ & $\begin{array}{l}228 \\
326^{\star}\end{array}$ & $\begin{array}{l}256 \\
301^{\star}\end{array}$ \\
\hline $\begin{array}{l}\text { Gap } \\
\text { task }\end{array}$ & $\begin{array}{l}\text { Latency } \\
\text { (ms) } \\
\text { Accuracy } \\
\text { (gain) }\end{array}$ & $\begin{array}{l}\mathbf{R} \\
\mathbf{L} \\
\mathbf{R} \\
\mathbf{L}\end{array}$ & $\begin{array}{l}208(35) \\
206(30) \\
096(4.5) \\
0.97(6.4)\end{array}$ & $\begin{array}{l}192 \\
253 \\
0 \cdot 89 \\
0 \cdot 70^{\star}\end{array}$ & $\begin{array}{l}220 \\
253 \\
0.91 \\
0.80^{\star}\end{array}$ \\
\hline $\begin{array}{l}\text { Immobility } \\
\text { task }\end{array}$ & $\begin{array}{l}\text { Percentage } \\
\text { of errors }\end{array}$ & $\begin{array}{l}\mathbf{R} \\
\mathbf{L}\end{array}$ & $\begin{array}{l}0.4(0-2)^{b} \\
0.5(0-3)\end{array}$ & $\begin{array}{r}45 \\
5\end{array}$ & $\begin{array}{l}\mathbf{0} \\
\mathbf{0}\end{array}$ \\
\hline $\begin{array}{l}\text { Antisaccade } \\
\text { task }\end{array}$ & $\begin{array}{l}\text { Percentage } \\
\text { of errors }\end{array}$ & $\begin{array}{l}\mathbf{R} \\
\mathbf{L}\end{array}$ & $\begin{array}{l}14(0-38) \\
12(0-32)\end{array}$ & $\begin{array}{l}52 \\
50\end{array}$ & $\begin{array}{r}5 \\
37\end{array}$ \\
\hline
\end{tabular}

within the normal range. Vertical (upward and downward) saccades, vertical smooth pursuit and convergence were qualitatively normal.

\section{Discussion}

The persistence of qualitatively normal vertical eye movements indicates that the premotor structures involved in their control, such as the posterior commissure, were largely spared by the lesion. However; ; intermittent vertical diplopia, due to the impairment of the left superior oblique muscle, probably resulted from slight damage to the right trochlear nucleus or fibres, at the inferior part of the lesion. Our results suggest that the SC is involved in both the triggering and inhibition of reflexive visually-guided saccades.

Reflexive visually-guided saccades are made to visual targets suddenly appearing in the peripheral visual field. Before a shift of gaze towards a lateral target, a disengagement of visual attention directed to the central fixation point is necessary, which takes some time. ${ }^{9}$ In normal subjects, latency is slightly shorter in the gap task than in the overlap task because the former task facilitates a disengagement of visual attention before the onset of the lateral target. ${ }^{9}$ At the first examination, latency in our patient was clearly increased for leftward saccades in the overlap task and slightly increased for the same saccades in the gap task, with significant asymmetry between rightward and leftward saccade latencies in both tasks. Such asymmetry and increased saccade latency contralaterally to the lesion confirm the results of previous experimental and clinical studies, ${ }^{3-6}$ and are not surprising given the lateralised organisation of the SC. ${ }^{10} \mathrm{~A}$ clear increase in saccade latency in the overlap task, still persisting at the second examination, could not be explained by a disorder in peripheral visual attention since there was no visual neglect in this patient. On the other hand, this increase in latency could largely result from a disorder in disengagement of visual attention from the central fixation point. It has been suggested that the parietal lobe is involved in disengagement of visual attention. ${ }^{11}$ As the parietal lobe projects directly onto the $\mathrm{SC},{ }^{12}$ disengagement of visual attention could be controlled by this pathway.

Though latency was less impaired in the gap task, it was abnormal, since there was significant asymmetry between rightward and leftward saccade latencies at the first examination. The existence of such an abnormality suggests that the $\mathrm{SC}$ is also involved in the control of reflexive visually-guided saccades elicited with the gap task. The only slight increase in latency of contralateral saccades observed in this task could be due to the existence of an adaptive mechanism, perhaps already partially effective by the time of the first eye movement recordings. It appears probable, from experimental studies, ${ }^{1}$ that a direct fronto-reticular tract replaces the pathway passing through the SC when this structure is damaged. Finally, a varying degree of involvement of the SC in the overlap task and the gap task could account for the relatively slight increase, when compared with controls, in the difference existing between latencies of these two tasks. Furthermore, reflexive visually-guided saccades made contralaterally to the lesion were hypometric in our patient, at both examinations. This disorder could be due to damage to the brachium conjunctivum, or more probably to the SC, since it has been reported that lesions affecting this structure result in contralateral hypometric saccades. ${ }^{346}$ These data suggest that the $\mathrm{SC}$ is also involved in the amplitude calibration of reflexive visually-guided saccades.

High percentages of unwanted reflexive saccades were observed in the immobility task and the antisaccade task at the first examination. That these percentages of errors returned to normal or near normal at the second examination suggests that they were abnormally high at the first examination because of the SC lesion. The increase in the percentage of errors was clearly more marked for rightward saccades in the immobility task, but existed both for rightward and leftward saccades in the antisaccade task at the first examination. This dissociation of results suggests that there was either a failure of two separate inhibitory mechanisms or the impairment of a single inhibitory mechanism, involved differently in each paradigm. Abnormally frequent unwanted rightward saccades in the immobility task could result from a disinhibition of the left SC, caused by the right SC lesion, since both sides of the SC are normally linked by reciprocal inhibitory connections. ${ }^{10}$ However, the functional role of such connections is not well known, and this mechanism is insufficient to account for unwanted reflexive saccades occurring in both 
directions of gaze in the antisaccade task.

It has been suggested that the dorso-lateral prefrontal cortex (or area 46 of Brodmann) controls the inhibition of unwanted reflexive saccades in the antisaccade task, ${ }^{13}$ but little is known about the pathways through which this control is exerted. The impairment of inhibition could take place at the premotor reticular level, where the omnipause neurons (OPN) tonically inhibit the premotor neurons of the paramedian pontine reticular formation (PPRF). ${ }^{14}$ It has been suggested that the rostral part of the SC contains tecto-reticular neurons projecting on to the OPN. ${ }^{15}$ It may be that these neurons reinforce or maintain the OPN activity during certain tasks, such as fixation, ${ }^{15}$ to prevent unwanted reflexive saccades. The impairment of this collicular control could result in a partial lack of inhibition of the PPRF. neurons and, consequently, in abnormally frequent unwanted reflexive saccades. These saccades occurred in both directions in the antisaccade task perhaps because either the rostral tecto-reticular neurons of each side of the SC contribute to the inhibition of saccades in all directions or the lesion of the right SC was partly affecting the left SC by compression at the first examination. The improvement of results in the immobility and antisaccade tasks at the second examination could result from either the recovery of the initially damaged SC cells (on one or both sides) or the development of adaptive mechanisms. Finally, our results suggest that the SC contributes to both the triggering and inhibition of reflexive visuallyguided saccades, though other studies are needed to determine the precise mechanisms involved in these functions.

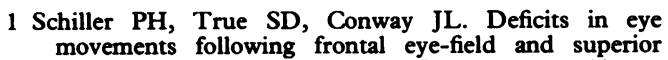
colliculus ablations. J Neurophysiol 1980;44:1175-89.

2 Pierrot-Deseilligny C. Cortical control of saccades. Neuroophthalmology 1991;11:63-75.

3 Hikosaka $O$, Wurtz RH. Modification of saccadic eye movements by GABA-related substances. I. Effect of muscimol and bicuculline in monkey superior colliculus. muscimol and bicuculline in monk

4 Hikosaka O, Wurtz RH. Saccadic eye movements following injection of lidocaine into the superior colliculus. Exp Brain Res 1986;61:531-9.

5 Schiller PH, Sandell JH, Maunsell JHR. The effect of frontal eye field and superior colliculus lesions on saccadic latencies in the rhesus monkey. $J$ Neurophysiol 1987; 57:1033-49.

6 Heywood S, Ratcliff G. Long-term oculomotor consequences of unilateral colliculectomy in man. In: Lennestrand $G$, Bach-y-Rita P, eds. Basic mechanisms of ocular motility and their clinical implications. Oxford: Pergamon Press, 1975:561-4.

7 Chain F, Leblanc M, Chedru F, Lhermitte F. Négligence visuelle dans les lésions postérieures de l'hémisphère vauche. Rev Neurol 1979;135:105-26.

8 Pierrot-Deseilligny C, Amarenco P, Roullet E, Marteau R. Vermal infarct with pursuit eye movement disorders. Vermal infarct with pursuit eye movement
$J$ Neurol Neurosurg Psychiat 1990;53:519-21.

9 Fischer B. The preparation of visually guided saccades. Rev physiol biochemist pharmacol 1987;106:1-35.

10 Grantyn R. Gaze control through superior colliculus: structure and function. In: Büttner-Ennever JA, ed. Neuroanatomy of the oculomotor system. Amsterdam: Elsevier, 1988:273-333.

11 Posner MI, Walker JA, Friedrich FJ, Rafal RD. Effects of parietal injury on covert orienting of attention. $J$ Neuroscience 1984;4:1863-74.

12 Lynch JC, Graybiel AM, Lobeck LJ. The differential projection of two cytoarchitectonic subregions of the inferior parietal lobule of macaque upon the deep layers of the superior colliculus. J Comp Neurol 1985;235:241-54.

13 Pierrot-Deseilligny C, Rivaud S, Gaymard B, Agid Y. Cortical control of reflexive visually-guided saccades. Brain 1991;114:1473-85.

14 Büttner-Ennever JA, Büttner U. The reticular formation. In: Büttner-Ennever JA, ed. Neuroanatomy of the oculomotor system. Amsterdam: Elsevier, 1988:119-76.

15 Munoz DP, Guitton D. Fixation and orientation control by the tecto-reticulo-spinal system in the cat whose head is unrestrained. Rev Neurol 1989;145:567-79. 